\title{
Addressing the Soft Tissue Element in Unilateral Cleft Lip Nasal Deformity
}

Ahmed Mohamed Elamin Khaled ${ }^{a}$, Ashraf Mahmoud Khaled ${ }^{a}$ Mahmoud Fawzy Elbastar ${ }^{b}$, and Mohammed Ahmed Abd Eltawb ${ }^{a}$

${ }^{a}$ Otorhinolaryngology department, Faculty of Medicine, Beni-Suef University, Egypt

${ }^{\mathrm{b}}$ Otorhinolaryngology department, Faculty of Medicine, Cairo University, Egypt

\begin{abstract}
:
The goal of this study is to address the soft tissue element of this deformity (in addition to the essential skeletal element) and evaluate its value in the final outcome. Soft tissue element includes modifying the shape of the nostril by direct incisions and augmenting the nasal sill by composite grafts. The current study is a randomized controlled trial study performed. Twenty patients with unilateral cleft lip nasal deformity were included during the period from November 2016 to December 2018. Patients were recruited from Otorhinolaryngology outpatient clinics in Beni-Suef University Hospital and randomly allocated into two groups: group (A) included 10 patients underwent skeletal reconstruction only (standardized technique), while group (B) included 10 patients underwent, in addition to skeletal reconstruction, and soft tissue manipulation (the new technique). The results showed that there was no statistical difference between both groups regarding hemicolumellar length, hemitip height, alar width length and domal angel. Linear and angular measurements showed improvement in both groups without difference. Subjectively, patient satisfaction and peer review showed no significant difference.
\end{abstract}

Keywords: Unilateral Cleft lip nose, Primary cleft lip nasal deformity repair, soft tissue

\section{Introduction:}

Cleft lip deformity usually accompanies cleft lip. It is caused by displacement of alar cartilage, malposition of columella, lower skeleton of the nose, and nasal septum. The most important cause of nasal deformity is displacement of alar cartilage (1).
The unilateral cleft lip nasal deformity (UCLND) is complex deformity and affects all layers of tissues. Skeletal platform, inner lining, and osseocartilaginous structure and overlying skin can be affected in UCLND (2). 
UCLND is affected by many factors. The most important factor is the skeletal affection. The most affected part is lower lateral cartilage (LLC). LLC forms of affection are fragmentation and splay by the underlying cleft lip resulting in significant asymmetry in the nostrils that may continue even after lip repair (3).

The basic CLND depends on the extent of cleft of the lip. The secondary nasal defect is highly variable, and can be a result of the original malformation, any type of carried out surgery and growth of the nose and face. There is no standard surgical procedure has the ability to correct the CLND (4).

Most previous procedures are based on the skeletal repositioning. This includes moving of the cleft-side LLC and its repositioning into its original position. Another procedure included cleft-side LLC augmentation using cartilage grafts to enforce its weakness or elevate the nasal platform (2).

The primary correction of nasal deformity in cleft lip patients can impair of the development of the nose but, it is now greatly accepted that parallel correction of the CLND has no adverse effects on nasal growth (5).

Moreover, the primary rhinoplasty procedure in UCLND management has superior results because of its role nasal symmetry. After following up the long-term results of primary repair, it was concluded that there was no affection of growth by early surgery and the results remain stable up to 18 years of surgery (6).
Up till now, there is relative rare studies searching for outcomes in secondary cleft rhinoplasty also, there is high variability in secondary cleft nasal deformities and the surgical procedures done to correct them. While a few studies have looked at patient subjective outcomes and aesthetic outcomes, there are even fewer studies examining patient- reported or objective functional outcomes (7).

Aesthetic outcomes can be reported by the patients and surgeons. It has been reported that the aesthetic outcomes followed using both preoperative and postoperative photographic assessment in addition to newer technologies as 3dimensional laser surface scanning to assess 3 dimensional nasal changes following surgery (8).

Whilst there are no standardized measures to assess the outcome of cleft rhinoplasty, there are many tools available to assess functional outcomes. Despite, the lack of studies looking at functional outcomes; the nasal obstruction was a motivating factor in patients underwent secondary cleft rhinoplasty. This highlights the importance of functional considerations in secondary cleft rhinoplasty in addition to the aesthetic outcomes (9).

The aim of this thesis was to address the soft tissue element of this deformity (in addition to the essential skeletal element) and evaluate its value in the final outcome. Soft tissue element includes modifying the 
shape of the nostril by direct incisions and

grafts.

augmenting the nasal sill by composite

\section{Patients and Methods:}

The current study is a randomized controlled trial study performed. Twenty patients with unilateral cleft lip nasal deformity were included during the period from November 2016 to December 2018. Patients were recruited from Otorhinolaryngology outpatient clinics in Bani Suef University Hospital.

Patients were randomly divided in two groups: group (A) included 10 patients underwent skeletal reconstruction only (standardized technique), while group (B) included 10 patients underwent, in addition to skeletal reconstruction, and soft tissue manipulation (the new technique). Patients were randomly assigned to the groups, such that odd numbers were assigned to group (A) while even numbers were assigned to group (B).

\subsection{Inclusion and exclusion criteria:}

\section{1 -Inclusion criteria}

a-Unilateral cleft lip nasal deformity

b-At school age or older

\section{2 -Inclusion criteria}

a. Bilateral cleft lip nasal deformity

b. Syndromic patients with other craniofacial anomalies

c. Previous attempt(s) of rhinoplasty d. Any associated skin pathology affecting the area of the face.

e. Patients before 4 years of age

\subsection{All patients were subjected to:}

A. Preoperative assessment included the type of cleft lip closure and photodocumentation. All patients had preoperative portrait, lateral, oblique and basal views.

B. The nose was approached using the closed approach, in the form of infra-cartilaginous incisions in all cases. Dissection of both lower lateral cartilages was then performed in a subSMAS plane. Manipulation of the tip cartilages was performed by delivering both cartilages through one nostril. Skeletal reconstruction was performed for all patients in both groups. This implied medial and lateral inter-crural sutures to couple the prolapsed cleft-side cartilage to the normal one. Grafts were also needed and were designed to obtain symmetry between both lower lateral cartilages. Cartilage grafts were obtained from the conchal cartilage.

\section{Soft tissue manipulation (performed only in Group B) included the following techniques:}

a Nostril reshaping by Z-plasty performed at the corner of the nostril.

b. Sill grafts obtained from the healthy side and used to reconstruct the nasal sill on the cleft side.

c. Excision of skin at the soft triangle. 


\section{All surgical incisions were closed using}

5.0 absorbable sutures. Steristrips were applied and the nose splinted for one week using aluminum splint.

\section{E. Patients were discharged home in the} same day and were followed up for a minimum of 6 months. Photo-documentation was repeated during each follow up visit in the same manner as preoperative views.

F. Assessment was carried objectively and subjectively. Objective assessment was performed by obtaining measurements on the photos of the patients. Subjective assessment was based on the family of the patient as well as on peer review.

\section{G. Measurement parameters included:}

a-Linear measurement:

1. Hemi-columellar length

2. Hemi-tip Height

3. The domal angle

b-Linear measurement:

1.Alar Width: Distance between the most distal point on the ala and the columella (medial edge).

Measurements were obtained from portrait and basal views. Patients' photographs were projected on a white board. Measurements were then obtained by a ruler for linear values and a protractor for angular values. The degree of objective improvement is calculated by the difference between the values of the cleft side as compared to the normal side. In case of angular measurements, the difference is directly calculating by subtraction. In case of linear measurements, the difference is expressed in percent. Family's satisfaction was obtained by a VAS with a 3-level score system: $3=$ happy, $2=$ neutral (hardly any change) and $1=$ unhappy. Peer review was obtained by projecting the photos (in all views). Peers are asked to score the "symmetry of the nostrils" on a 10-point score, where score 1 is very poor result and score 10 is excellent result. Peers were blinded to the group of the patient.

H. Measurements and scores were then subjected to statistical analysis to compare the esthetic outcome in both groups and whether soft tissue manipulation rendered any appreciable improvement. No complications (such as bleeding or wound infection) were encountered.

\section{3 . Statistical analysis:}

Analysis of data was performed using SPSS v. 25 (Statistical Package for Social science) for Windows. Description of quantitative variables was done in the form of mean, standard deviation (SD), description of qualitative variables was done in the form of numbers (No.) and \%. Comparing between quantitative variables was carried out by independent t-test that was used to test the difference between the means of 2 groups of a scale variable. Comparing between categorical data was done using the Chi square test, to test the statistical difference between the 2 groups. The significance of the results was assessed in the form of $\mathrm{P}$-value that was differentiated into 
non-significant when P-value > 0.05 and

significant when $\mathrm{P}$-value $\leq 0.05$.

\section{4 .Ethical Considerations and Review:}

Study protocol was approved by Faculty of Medicine, Beni-Suef University, Research Ethics Committee.

\section{Results:}

Both groups were well matched regarding their baseline characteristics. Eight patients (5 in group A versus 3 in group B) were males, while twelve were females ( 5 in group A versus 7 in group B). In group (A), the age ranged from 4 years to 15 years with an average age of $9.5 \pm 3.2$ years. In group (B), age ranged from 4 years to 12 years with a mean of $7.5 \pm 3.1$ years with there was no statistically significant difference in both groups regarding their age and sex $(\mathrm{P}$-value $>0.05)$.

Regarding the preoperative hemicolumellar length, it was $(3.6 \pm 0.83 \mathrm{~cm})$ in group A and $(4 \pm 1.1 \mathrm{~cm})$ in group B with no statistically significant difference between both groups (P-value $>0.05)$. The effect of both procedures on hemicolumellar length was followed up and shown in table (1).

Regarding the preoperative hemitip height, it was $(9.4 \pm 1.5 \mathrm{~cm})$ in group $\mathrm{A}$ and $(10.4 \pm 2.7 \mathrm{~cm})$ in group B with no statistically significant difference between both groups (Pvalue $>0.05)$. The effect of both procedures on hemitip height was followed up and shown in table (2).
As regard, the preoperative alar width length it was $(10.6 \pm 2.4 \mathrm{~cm})$ in group $\mathrm{A}$ and $(12.1 \pm 1.8 \mathrm{~cm})$ in group B with no statistically significant difference between both groups ( $\mathrm{P}$ value >0.05). The effect of both procedures on alar width length was followed up and shown in table ( 3 ).

Concerning the preoperative domal angel parameters was shown in table (4). The postoperative effect of the procedure done in group A (the domal angel parameter) decreased after the operation (from $73.5 \pm 14.50$ to $65 \pm 18.40)$ and this effect was significant (Pvalue $=0.004)$ and the effect of the procedure done in group B (domal angel parameter) was also decreased (from $77 \pm 4.8$ o to $68 \pm 7.528$ o) and also this effect was significant $(\mathrm{P}-\mathrm{value}=$ 0.008). The difference between the two groups after the operation was insignificant (P-value between groups postoperative $=0.693$ ) (table. 4)

The current study showed that no statistically significant differences were determined between both groups regarding their family satisfaction (group A $3 \pm 0.6 \%$ group B 3.4 $\pm 0.8 \%)(\mathrm{P}-\mathrm{value}=0.255)$ but there

is still more satisfaction among families in group B.

Regards the aesthetic assessment by the three experts in both procedures, there was no significant difference in agreement between both groups by the 1 st and the 2 nd doctors ( $\mathrm{P}$ value $>0.05$ between both groups by the two experts) but the third one preferred procedure 
$\mathrm{B}$ in improving the aesthetic outcome $(\mathrm{P}-$ value $=0.005)$ table. $) 5($

Regards the agreement between the three experts, there was no significant difference in agreement in each group by the 3 experts table

Table (1): Comparison between both groups regarding the difference in HEMICOL LENGTH before and after surgery.

\begin{tabular}{|c|c|c|c|c|c|}
\hline \multicolumn{3}{|c|}{$\begin{array}{c}\text { HEMICOL LENGTH } \\
\text { parameters }\end{array}$} & $\begin{array}{c}\text { Pre-operative } \\
\text { Mean } \pm \text { SD }\end{array}$ & $\begin{array}{c}\text { Post-operative } \\
\text { Mean } \pm \text { SD }\end{array}$ & P-value Pre-post \\
\hline \multirow{3}{*}{$\stackrel{1}{\circ}$} & \multirow{3}{*}{$\underbrace{\stackrel{\Xi}{0}}_{\frac{\mathbb{E}}{0}}$} & Group A & \multicolumn{2}{|c|}{$5.1 \pm 1$} & \\
\hline & & Group B & \multicolumn{2}{|c|}{$6.1 \pm 1.2$} & \\
\hline & & P-value between groups & 0.185 & 0.185 & \\
\hline \multirow{3}{*}{\multicolumn{2}{|c|}{ 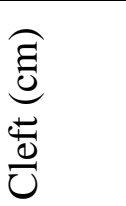 }} & Group A & $3.6 \pm 0.83$ & $4.1 \pm 1$ & $0.003 *$ \\
\hline & & Group B & $4 \pm 1.1$ & $5 \pm 0.9$ & $<0.001 * *$ \\
\hline & & P-value between groups & 0.303 & 0.052 & \\
\hline \multirow{3}{*}{\multicolumn{2}{|c|}{ 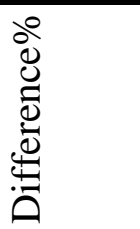 }} & Group A & $33.5 \pm 10.9$ & $23.9 \pm 10.8$ & $0.001 *$ \\
\hline & & Group B & $33.9 \pm 9.8$ & $16.8 \pm 7.5$ & $<0.001 * *$ \\
\hline & & P-value between groups & 0.927 & 0.106 & \\
\hline
\end{tabular}

Table (2) Comparison between both operations and their effect on the HEMITIP HEIGHT parameters

\begin{tabular}{|c|c|c|c|c|}
\hline \multicolumn{2}{|c|}{ HEMITIP HEIGHT parameters } & \multirow{2}{*}{$\begin{array}{c}\begin{array}{c}\text { Pre-operative } \\
\text { Mean } \pm \text { SD }\end{array} \\
10.5 \pm 1.6\end{array}$} & \multirow{2}{*}{$\begin{array}{c}\text { Post-operative } \\
\text { Mean } \pm \text { SD }\end{array}$} & \multirow{2}{*}{$\begin{array}{c}\text { P-value Pre- } \\
\text { post }\end{array}$} \\
\hline \multirow{3}{*}{$\stackrel{1}{\stackrel{1}{0}}$} & Group A & & & \\
\hline & Group B & $11.8 \pm 2.6$ & $11.8 \pm 2.6$ & \\
\hline & P-value between groups & 0.192 & 0.192 & \\
\hline \multirow{3}{*}{ 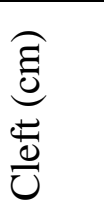 } & Group A & $9.4 \pm 1.5$ & $9.7 \pm 1.6$ & $0.010 *$ \\
\hline & Group B & $10.4 \pm 2.7$ & $11.1 \pm 2.5$ & $0.002 *$ \\
\hline & P-value between groups & 0.319 & 0.157 & \\
\hline \multirow{3}{*}{ 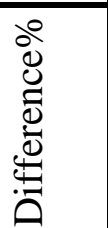 } & Group A & $10.7 \pm 2.1$ & $7.4 \pm 3$ & $0.010 *$ \\
\hline & Group B & $12.5 \pm 4.7$ & $6.5 \pm 4.3$ & $0.002 *$ \\
\hline & P-value between groups & 0.273 & 0.617 & \\
\hline
\end{tabular}


Table (3): Comparison between both operations and their effect on the Alar width parameters

\begin{tabular}{|c|c|c|c|c|}
\hline \multicolumn{2}{|c|}{ Alar width parameters } & \multirow{2}{*}{$\begin{array}{c}\text { Pre-operative } \\
\text { Mean } \pm \text { SD }\end{array}$} & \multirow{2}{*}{ 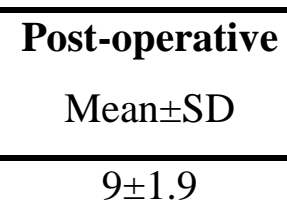 } & \multirow{2}{*}{$\begin{array}{c}\text { P-value } \\
\text { Pre-post }\end{array}$} \\
\hline \multirow{3}{*}{ 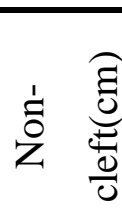 } & Group A & & & \\
\hline & Group B & $9.4 \pm 1.4$ & $9.4 \pm 1.4$ & \\
\hline & P-value between groups & 0.655 & 0.655 & \\
\hline \multirow{3}{*}{ 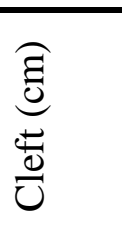 } & Group A & $10.6 \pm 2.4$ & $9.7 \pm 2.2$ & $<0.001 * *$ \\
\hline & Group B & $12.1 \pm 1.8$ & $10 \pm 1.7$ & $<0.001 * *$ \\
\hline & P-value between groups & 0.139 & 0.693 & \\
\hline \multirow{3}{*}{ 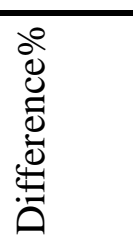 } & Group A & $17.3 \pm 6.5$ & $7 \pm 4.3$ & $<0.001 * *$ \\
\hline & Group B & $29.3 \pm 12.1$ & $10.2 \pm 5.3$ & $<0.001 * *$ \\
\hline & P-value between groups & $0.012 *$ & 0.181 & \\
\hline
\end{tabular}

Table (4) Comparison between both operations and their effect on the Domal angel parameters

\begin{tabular}{|c|c|c|c|c|}
\hline \multicolumn{2}{|c|}{ Domal angel parameters } & Pre-operative & Post-operative & P-value Pre- \\
\hline \multirow{3}{*}{$\begin{array}{l}\frac{5}{0} \\
\frac{1}{0} \\
i \\
\tilde{I} \\
Z\end{array}$} & Group A & $47 \pm 7.5$ & $47 \pm 7.5$ & \\
\hline & Group B & $46.5 \pm 7.5$ & $46.5 \pm 7.5$ & \\
\hline & $\begin{array}{c}\text { P-value between } \\
\text { groups }\end{array}$ & 0.883 & 0.883 & \\
\hline \multirow{3}{*}{ 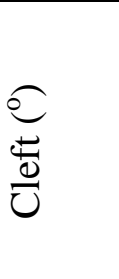 } & Group A & $73.5 \pm 14.5$ & $65 \pm 18.4$ & 0.004* \\
\hline & Group B & $77 \pm 4.8$ & $68 \pm 7.528$ & 0.008* \\
\hline & $\begin{array}{c}\text { P-value between } \\
\text { groups }\end{array}$ & 0.693 & 0.639 & \\
\hline \multirow{3}{*}{ 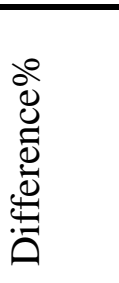 } & Group A & $26.5 \pm 14.2$ & $18 \pm 17.5$ & $0.004 *$ \\
\hline & Group B & $30.5 \pm 7.6$ & $21.5 \pm 11.1$ & 0.008* \\
\hline & $\begin{array}{c}\text { P-value between } \\
\text { groups }\end{array}$ & 0.600 & 0.605 & \\
\hline
\end{tabular}


Table (5) Aesthetic assessment of the three experts after the operation between both groups.

\begin{tabular}{|c|c|c|c|c|}
\hline Doctors & Groups & Mean & $\begin{array}{c}\text { Std. } \\
\text { Deviation }\end{array}$ & $\begin{array}{c}\text { P-value between } \\
\text { groups }\end{array}$ \\
\hline \multirow{2}{*}{ First } & Group A & 6.9 & 0.78 & 0.999 \\
\cline { 2 - 4 } & Group B & 6.8 & 0.76 & \\
\hline \multirow{2}{*}{ Second } & Group A & 6.6 & 0.84 & 0.999 \\
\cline { 2 - 4 } & Group B & 6.6 & 0.51 & \\
\hline \multirow{2}{*}{ Third } & Group A & 5.6 & 0.51 & \multirow{2}{*}{$\mathbf{0 . 0 0 5}^{*}$} \\
\cline { 2 - 4 } & Group B & 6.6 & 0.84 & \\
\hline
\end{tabular}

Table (6) Agreement between the three experts regarding the improvement after the operation in each group.

\begin{tabular}{|c|c|c|c|c|}
\hline Groups & Degree & Doctor 1 & Doctor 2 & Doctor 3 \\
\hline \multirow{3}{*}{$\begin{array}{c}\text { Group A } \\
(\mathbf{N = 1 0})\end{array}$} & $\mathbf{5}$ & $0(0)$ & $0(0)$ & $4(40)$ \\
\cline { 2 - 6 } No. (\%) & $\mathbf{6}$ & $4(40)$ & $6(60)$ & $6(60)$ \\
\cline { 2 - 6 } & $\mathbf{7}$ & $4(40)$ & $2(20)$ & $0(0)$ \\
\hline \multirow{2}{*}{ Mean \pm SD } & $\mathbf{8}$ & $6.9 \pm 0.78$ & $6.6 \pm 0.84$ & $5.6 \pm 0.51$ \\
\hline \multirow{3}{*}{$\begin{array}{c}\text { Group B } \\
(\mathbf{N}=\mathbf{1 0})\end{array}$} & $\mathbf{5}$ & $0(0)$ & $0(0)$ & $2(20)$ \\
\cline { 2 - 6 } No (\%) & $\mathbf{6}$ & $4(40)$ & $4(40)$ & $0(0)$ \\
\cline { 2 - 6 } & $\mathbf{7}$ & $4(40)$ & $6(60)$ & $8(80)$ \\
\hline \multicolumn{2}{|c|}{ Mean \pm SD } & $2(20)$ & $0(00$ & $0(0)$ \\
\hline
\end{tabular}




\section{Discussion:}

The current study showed improvement in both studied groups and there were similar results of skeletal reconstruction only and the addition soft tissue manipulation to skeletal reconstruction in improving the hemicolumellar length, hemitip height, alar width length and domal angel.

The improvement in the soft tissue group was approved by previous studies as Masuoka and colleagues' study in 2012 use

Photogrammetric analysis in 38 consecutive patients who had been treated by open rhinoplasty using the conchal cartilage between 2003 and 2009. Measurements were obtained from both preoperatively and 1 year or later postoperatively. The nasal height, nostril height and columella angle on the basilar view of the nose were measured. Photogrammetric analysis demonstrated a significant increase in the nasal height to nasal width ratio, a significant increase in the nostril height to nostril width ratio of the affected side and a slight improvement of the columella angle also all postoperative values are different from preoperative values, with statistical significance $(\mathrm{p}<0.01)(10)$.

These results of the differences between both procedures were not so far from many studies that described various techniques involving the use of cartilage grafts with or without skin and soft tissues to address unilateral cleft-lip nasal deformities with the same results as in as study that used conchal grafts within the nasal tip and columella (11). Another study used a gull-wingshaped conchal graft to provide additional support to the nasal tip (12). In addition to another research that used conchal cartilage to augment the nasal tip and perialar sulcus (13).

Another study used conchal composite grafts to elevate the lateral crus of the alar cartilage above the depressed piriform aperture (14). Ayhan and colleagues in 2006 published a series of cases where composite conchal cartilage was used in various forms to repair columellar deficit, to form nasal tubercle and nostril sill in cleft lip nasal deformity patients and concluded that use of conchal cartilage achieved symmetric and functional results (15).

Morever another research reported that subcutaneous undermining was broadly carried out over the entire lower two-thirds of the nose, including the upper part of the columella, and the alar cartilage on the affected side was sutured to the alar cartilage of the normal side and to the lateral cartilages on both the cleft and the non-cleft side with three sutures. In the few postoperative cases in this period that tended to relapse, such postoperative deformities appeared to be related to the alar cartilage relapsing into its former position (16).

Flores et al., in 2009 published a retrospective technique where a combination of Dibbell and Tajima was used and concluded that there was a 
statistically significant decrease in alar base width, increase in columellar height and nostril height on the affected side (17).

In Metz and colleagues in 2015 retrospective study that included 30 adult patients underwent secondary nasal entrance corrections. According to a modified Van der Meulen technique, a nasal alar rim triangular flap with anatomic repositioning of the alar cartilage was applied. The nasal tip was narrowed considerably, and a lifting of the nasal tip was achieved. And the form of the nostril was changed from horizontally oval to longitudinally oval. A disadvantage of this technique is that the achievable increase in columellar length is limited owing to the extent of excess skin at the edge of the alar rim. Another disadvantage is that no correction of the broadened base of the alae of the nose can be achieved through this surgery. Also, when viewed from below; the affected nostril appears slightly larger than the nostril on the healthy side (18).

Haddock and colleagues in 2012 in their study use Standard preoperative and postoperative photometric measurements (nostril dome height, nostril apex height and alar width) to compare long term effect of primary Cleft rhinoplasty on secondary cleft rhinoplasty in Patients with unilateral cleft Lipcleft Palate. They conclude that Primary nasal reconstruction performed with cleft lip repair makes the nasal tip more symmetric and requires less complex intervention at the time of definitive secondary rhinoplasty (19).
Aesthetic outcomes have been studied both through subjective assessment by patients and surgeons. Some studies have looked at aesthetic outcomes using both preoperative and postoperative photographic assessment $(7,20)$. Regarding the aesthetic outcome in the current study, there was a significant improvement in both groups but there was no statistically significant difference between both procedures among families and expert doctors. Although objective, quantitative outcome measures have an important role in facial plastic surgery, it could be argued that patient satisfaction is ultimately what matters the most. Overall, patient subjective outcomes following secondary cleft rhinoplasty tend to be positive with a relatively high satisfaction rate. Hens and colleagues in 2011 surveyed 30 patients who underwent secondary cleft rhinoplasty regarding nasal function and general satisfaction of the procedure using the validated Rhinoplasty Outcome Evaluation (ROE). They found that there was significant subjective improvement in ROE scores and in specific scores for aesthetic appearance (9).

Most studies have considered the opinions and evaluations of others, rather than those of the patients $(21,22)$.

In Han and Choi in 2001 study that conducted to assess the outcome of the three-dimensional $\mathrm{Z}$ plasty in correction of unilateral cleft lip nasal deformity was judged by two blinded observers (plastic surgeons) and rated excellent, good, satisfactory, or poor. Most of the patients were rated good or excellent (23). 


\section{Conclusion and Recommendations:}

It is concluded that no statistical difference between both groups. Linear and angular measurements showed improvement in both groups without difference. Subjectively, patient satisfaction and peer review showed no significant difference. Only one of the peers who reviewed the patients' photographs reported better outcome in group (B), with soft tissue manipulation. However, the overall statistical data did not show any difference.

Skin transposition at the area of the nasal dome showed very promising results in the early postoperative period, however, with continuous follow up, fibrosis and scarring blurred the initial results. The result was minimal (if any) improvement in the shape of the nostril.

The skeletal repositioning and reconstruction may for the time being be the only way to address the challenging problem of the unilateral cleft lip nasal deformity. Skin and soft tissue manipulation end up by contractures and scarring that totally blur the initial improvement seen on table right after surgery. Therefore, with the soft tissue techniques used in this study, it is not recommended to address the skin element of the deformity.

\section{References:}

1. Kim SK, Cha BH, Lee, KC, Park JM. Primary correction of unilateral cleft lip nasal deformity in Asian patients: anthropometric evaluation. Plastic and reconstructive surgery, 2004; 114(6): 1373-1381.
2. Gubisch, W. The triple swing flap technique to correct the asymmetry of unilateral cleft lip nose deformities. Scandinavian journal of plastic and reconstructive surgery and hand surgery, 1998; 32(3): 287-294.

3. Agarwal R, Chandra R. The septospinal ligament in cleft lip nose deformity: study in adult unilateral clefts. Plastic and reconstructive surgery, 2007; 120(6): 1633-1640.

4. Mazzola RF. Secondary unilateral cleft lip nose. External approach. Facial plastic surgery J. 1996; 12: 367- 78.

5. Kim SK, Cha BH, Lee KC, Park JM. Primary correction of unilateral cleft lip nasal deformity in Asian patients: anthropometric evaluation. Plastic and reconstructive surgery, 2004; 114(6): 1373- 1381.

6. Mccomb, HK, Coghlan BA. Primary repair of the unilateral cleft lip nose: completion of a longitudinal study. The Cleft palatecraniofacial journal, 1996; 33(1): 23-31.

7. Huempfner-Hierl $\mathrm{H}$, Hemprich A, Hierl $\mathrm{T}$. Results of a prospective anthropometric and functional study about aesthetics and nasal respiration after secondary rhinoplasty in cleft lip and palate patients. Journal of Craniofacial Surgery, 2009; 20(8): 1863-1875.

8. Okawachi $T$, Nozoe $E$, Nishihara $K$, Nakamura N. 3-dimensional analyses of outcomes following secondary treatment of unilateral cleft lip nose deformity. Journal of Oral and Maxillofacial Surgery, 2011; 69(2): 322-332. 
9. Hens G, Picavet VA, Poorten VV, Schoenaers J, Jorissen M, Hellings PW. High patient satisfaction after secondary rhinoplasty in cleft lip patients. In International forum of allergy \& rhinology, 2011; 1(3): 167172.

10. Masuoka H, Kawai K, Morimoto N, Yamawaki S, Suzuki S. Open rhinoplasty using conchal cartilage during childhood to correct unilateral cleft- lip nasal deformities. Journal of plastic, reconstructive \& aesthetic surgery, 2012; 65(7): 857-863.

11. Pollet J. Three autogenous struts for nasal tip support. Plastic and reconstructive surgery, 1972; 49(5): 527-532.

12. Falces E. Use of ear cartilage grafts for nasal tip reconstruction. Plast Reconstr Surg.1972; 50:147-52.

13. Thomson HG. (1985). The residual unilateral cleft lip nasal deformity: a threephase correction technique. Plastic and reconstructive surgery, 1985; 76(1): 36-43.

14. Matsuo K, Hirose T. Secondary correction of the unilateral cleft lip nose using a conchal composite graft. Plastic and reconstructive surgery, 1990; 86(5): 991995.

15. Ayhan M, Gorgu M, Erdogan B, Aytug Z, Aksungur E, Sy O, Oztan Y. Various applications of chondrocutaneous composite grafts in secondary cleft lip nose patients. Journal of Craniofacial Surgery, 2006; 17(6): 1065-1071.

16. Tajima SADAO, Maruyama MASARU. Reverse-U incision for secondary repair of cleft lip nose. Plastic and reconstructive surgery, 1977; 60(2): 256-261.

17. Flores, RL, Sailon AM. A novel cleft rhinoplasty procedure combining an open rhinoplasty with the Dibbell and Tajima techniques: a 10-year review. Plastic and reconstructive surgery, 2009; 124(6): 20412047.

18. Metz AS, Pfortner R, Schmeling C, Rieger G, Mohr C. Nasal Entrance Correction in Cleft Lip Repair. J Oral Maxillofac Surg.2015; 73: 2038 e7.

19. Haddock NT, McRae MH. Long-term effect of primary cleft rhinoplasty on secondary cleft rhinoplasty in patients with unilateral cleft lip-cleft palate. Plastic and reconstructive surgery, 2012; 129(3): 740748.

20. Pitak-Arnnop P, Hemprich A, Dhanuthai K, Yildirim V, Pausch NC. Panel and patient perceptions of nasal aesthetics after secondary cleft rhinoplasty with versus without columellar grafting. Journal of Cranio-Maxillofacial Surgery, 2011; 39(5): 319-325.

21. Gurley JM, Pilgram T, Perlyn CA, Marsh JL. Long-term outcome of autogenous rib graft nasal reconstruction. Plastic and reconstructive surgery, 2001; 108(7): 18951905.

22. Kane AA, Pilgram TK, Moshiri M, Marsh JL. Long- term outcome of cleft lip nasal reconstruction in childhood. Plastic and reconstructive $\quad$ surgery, 2000; 105(5):1600-1608.

23. Han S, Choi MS. Three-dimensional z-plasty in the correction of the unilateral cleft lip nasal deformity. The Cleft palate-craniofacial journal, 2001; 38(3): 264-267. 
